\section{Chlamydia trachomatis detection in HIV infected patients using polymerase chain reaction}

\author{
Shrestha A,1ø Adhikari N,1,2ø* Shah Y,1ø \\ Poudel P,1ø Acharya B, ${ }^{1}$ Pandey BD ${ }^{1}$
}

${ }^{1}$ Everest International Clinic and Research Center, Kathmandu, Nepal; ${ }^{2}$ Department of Microbiology, Janaki Medical College, Janakpur, Nepal.

${ }^{\varnothing}$ The authors have equal contribution

*Correspondence to: Mr. Nirakar Adhikari, Department of Microbiology, Janaki Medical College, Janakpur, Nepal, email: nirakar.adhikari@gmail.com, Tel. No.: (+977)-9841878117

\begin{abstract}
INTRODUCTION: Chlamydia trachomatis is a sexually transmitted organism and causes important public health problem in the sexually active age group. Limited studies are found regarding the prevalence of $C$. trachomatis in Nepal.This study attempts to determine the burden of chlamydia on HIV positive patients.
\end{abstract}

MATERIALS AND METHODS: A total of 117 HIV positive patients visiting a HIV clinic in Kathmandu, were screened for chlamydia infection. For this, urine samples were collected and analyzed using the Polymerase Chain Reaction Technique (PCR).

RESULTS: $C$. trachomatis was detected in $4.2 \%$ of the total 117 HIV patients. Out of positive cases $60 \%$ were males and $40 \%$ were females. Eighty percent of positive cases were asymptomatic.

CONCLUSIONS: Although, the prevalence of chlamydia infection was found less in HIV patients, most of those cases were asymptomatic. Therefore, routine checkup is recommended for all suspected cases for timely management of the disease.

KEY WORDS: HIV, Sexually transmitted infection (STI), Multiplex Polymerase Chain Reaction, Nepal

Article submitted 23 December 2012. Reviewed 12 January. Author correction 11 February. Final version accepted 27 February 2013. 


\section{INTRODUCTION}

Chlamydia trachomatis is an intracellular bacterium which causes genital tract infections. Human are its natural host. ${ }^{1}$ It causes one of the most common treatable sexually transmitted disease (STD) among sexually active group. ${ }^{2}$ Chlamydia can be transmitted by vaginal, oral or anal sex, putting homosexual men at risk as well. Chlamydia infections can also be passed down from an infected mother to her baby during vaginal childbirth. ${ }^{3}$

Chlamydia disease is a "silent disease", with approximately $75 \%$ of infected women and $50 \%$ of infected men showing no symptoms. If symptoms occur, they usually occur within one to three weeks after exposure. ${ }^{4}$ Symptomatic patient may have discharge from penis/vagina or burning and itching around the genital opening and inflammation of the testicles,5,6 and may lead to sterility and pelvic inflammatory disease. ${ }^{7}$

People with STD are more likely to be infected with HIV as they provide easy passage for the virus to enter the blood streams via the genital ulcerations. STI increases both the infectivity of persons with HIV and the susceptibility of those with STIs to HIV infection. ${ }^{8}$ Chlamydia infection is an important biological behavioral marker in HIV infected individuals that may expose others to HIV Furthermore, chlamydia is associated with increased cervico-vaginal HIV shedding that may increase HIV transmissibility. ${ }^{9}$

Chlamydia infection is an important public health problem in the sexually active age group. Very few studies appear regarding the prevalence of $C$. trachomatis in Nepal. The current study was conducted to determine the burden of chlamydia on HIV positive patients using PCR technique.

\section{MATERIALS AND METHODS}

This is a cross-sectional study carried out among HIV positive cases visiting HIV clinic of Sparsha Nepal from $15^{\text {th }}$ January 2011 to $30^{\text {th }}$ March, 2011. Demographic data and other information were collected using data collection sheet and questionnaire through interview. A total of 117 samples were collected and processed for DNA isolation, amplification and detection using agarose gel electrophoresis. ${ }^{10}$

Sample collection and processing: The urine sample was collected and preprocessed using standard protocol. Briefly, from each sample, $10 \mathrm{ml}$ of urine was taken for centrifugation at $7500 \mathrm{rpm}$ for 10 minutes. The pellet was collected in a clean and sterile test tube, washed with 10-15 ml PBS and re-centrifugation was done at $5000 \mathrm{rpm}$ for 15 minutes. Then, $200 \mu \mathrm{l}$ PBS was added to the pellet, transferred to $1.5 \mathrm{ml} \mathrm{micro-centrifuge} \mathrm{tubes} \mathrm{and}$ stored at $2-8^{\circ} \mathrm{C}$. The processed samples were transported to Everest International Clinic and Research Center (EICRC) for further processing.

DNA isolation, amplification and detection: DNA was extracted as per the standard QIAamp DNA mini kit and handbook protocol (Lot no. 42710823, Cat. no.51306). This DNA sample was used directly for quantification and PCR. Isolated DNA was subjected to amplification using "MPCR kit for sexually transmitted diseases CTR/UU/NG" by Maxim Biotech. Inc., California, USA. In this amplification process the primers were used to amplify $364 \mathrm{bp}$ region of cryptic plasmid gene of $C$. trachomatis. Each $50 \mu \mathrm{l}$ PCR reaction mixture contained, $25 \mu \mathrm{l} 2 \mathrm{X}$ MPCR buffer mixture, $5 \mu \mathrm{l} 10 \mathrm{X}$ MPCR primers, $0.5 \mu \mathrm{l}$ Taq Polymerase $(5 \mathrm{U} / \mu \mathrm{l}), 14.5$ $\mu \mathrm{l}$ Water $\left(\mathrm{H}_{2} \mathrm{O}\right)$ and $5 \mu \mathrm{l}$ DNA sample. For negative and positive controls, water and positive control provided in the kit were used respectively. The PCR profile used was: 2 cycles of $96^{\circ} \mathrm{C}$ for $1 \mathrm{~min}$ followed by $65^{\circ} \mathrm{C}$ for $4 \mathrm{~min} ; 35$ cycles of $94^{\circ} \mathrm{C}$ for $1 \mathrm{~min}$ followed by $65^{\circ} \mathrm{C}$ for $2 \mathrm{~min}$; 1 cycles of $70^{\circ} \mathrm{C}$ for 10 min and at $25^{\circ} \mathrm{C}$ (for soaking). The PCR product (364 bp) was detected using 1\% TAE gel electrophoresis.

Data Analysis: Statistical analysis was done and data was analyzed by using the statistical software SPSS version 13. The association between categorical variable was done using Chi-square test. The p-value less than 0.05 was considered significant.

\section{RESULTS}

Among 117 urine samples, 29 (24.79\%) were of females and $88(75.21 \%)$ were of males. The age of patients ranged from 20-64 years. The highest number of cases $(n=74,63.5 \%)$ belonged to age group 25-40 years.

\section{Prevalence of Chlamydia}

Out of the total 117 urine samples collected, only 5 (4.27\%) were positive for $C$. trachomatis (Figure) and 112 (95.73\%) were negative. Prevalence of $C$. trachomatis in males was $3.4 \%$ and that among females was $6.9 \%$. Three positive male were of age 23,27 and 35 years. On the other hand two positive females were 21 and 22 years of age. No significant difference was observed between $\operatorname{sex}\left(\chi^{2}, 6.8 ; \mathrm{p}\right.$, 
Table 1. Prevalence of chlamydia according to age group and sex

\begin{tabular}{lccccccc}
\hline Age Group (years) & Total Patients & \multicolumn{3}{c}{ Male } & \multicolumn{2}{c}{ Female } \\
\cline { 3 - 8 } & & Total & Positive & Positive $\%$ & Total & Positive & Positive \% \\
\hline $20-30$ & 42 & 30 & 2 & 6.7 & 12 & 2 & 16.7 \\
$31-40$ & 46 & 37 & 1 & 2.7 & 9 & 0 & 0 \\
$41-50$ & 23 & 16 & 0 & 0 & 7 & 0 & 0 \\
$51-60$ & 5 & 5 & 0 & 0 & 0 & 0 & 0 \\
$61-70$ & 1 & 0 & 0 & 0 & 1 & 0 & 0 \\
Total & 117 & 88 & 3 & 3.4 & 29 & 2 & 6.9 \\
\hline
\end{tabular}

Association between disease occurrence and $\operatorname{sex}\left(\chi^{2}, 6.8 ; p, 0.44\right)$

Association between disease occurrence and age group $\left(\chi^{2}, 4.6 ; p, 0.33\right)$

Table 2. Distribution of chlamydia cases according to marital status

\begin{tabular}{lcccc}
\hline Marital status & Number of cases & Positive & Negative & Positive \% \\
\hline Married & 98 & 5 & 93 & 5.10 \\
Unmarried & 19 & 0 & 19 & 0 \\
Total & 117 & 5 & 112 & 4.27 \\
\hline
\end{tabular}

$0.44)$ and also the age group $\left(\chi^{2}, 4.6 ; \mathrm{P}, 0.33\right)$.

\section{Chlamydia positive cases according to symptoms and gender}

Most cases $(n=4)$ were asymptomatic. One male case was symptomatic with urethral discharge. Statistically, there was no significant difference between the symptomatic cases and disease occurrence $(\chi 2,0.42 ; p, 0.51)$. Likewise, association between asymptomatic cases and disease occurrence was insignificant $(\chi 2,1.68 ; \mathrm{p}, 0.19)$. Association between marital status and disease occurrence $\left(\chi^{2}, 1.01 ; p, 0.31\right)$ As shown in table 2 , all of the positive cases were married. Despite this, there was no statistically significant association between marital status and the occurrence of disease.

\section{Knowledge of STI among Patients}

Out of the total 117 cases, only 15 (12.8\%) had knowledge of STI where as 102 (87.2\%) had no knowledge about the STI. Among the positive cases, two (40\%) had knowledge, whereas remaining three $(60 \%)$ had no knowledge of STI. Statistically, there was no significant association between the knowledge about the disease and the occurrence of the disease $\left(\chi^{2}, 3.35 ; \mathrm{p}, 0.067\right)$.

\section{DISCUSSION}

Nucleic acid amplification technique like PCR has been used in our study because of its high sensitivity, specificity and rapidity in comparison to conventional culture and serological techniques. There is currently no laboratory in Nepal that offers the chlamydia culture. Neither any antigen detection techniques are more sensitive and specific than

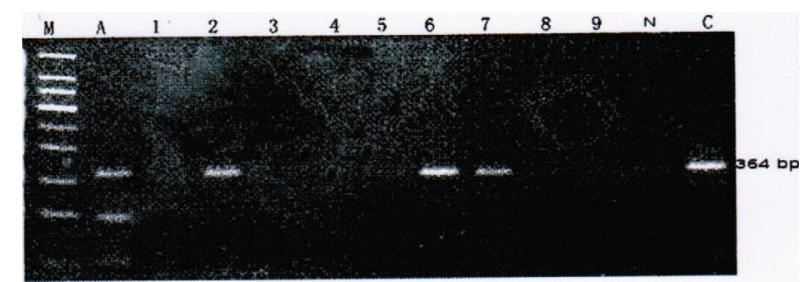

Figure. 1\% Gel electrophoresis of amplified PCR products. Lane M, 100bp Molecular weight marker; Lane A and 1 to 9, test samples; Lane $\mathrm{N}$, negative control; and lane $\mathrm{C}$, positive control. Non-specific bands at $100 \mathrm{bp}$ and $200 \mathrm{bp}$ were noted for sample A.

culture techniques. PCR was found to be $100 \%$ sensitive and specific while detecting $C$. trachomatis among female sex workers in Singapore. ${ }^{11}$ Even a single organism was said to be detected by PCR with very high sensitivity, specificity and higher predictive values. ${ }^{12}$ In the former study, the prevalence was much higher by PCR (4.1\%) compared to the one obtained by antigen detection techniques like Enzyme immunoassays (EIA) $(1.6 \%)$. This prevalence rate as a whole is also in agreement with our study. Less sensitive methods such as EIA result in under-treatment of otherwise undetected cases. PCR based study are of prime importance in such issues. This study, using PCR, clearly showed prevalence of $C$. trachomatis (4.27\%) among HIV patients visiting HIV clinics in Nepal. Female population was found to be more susceptible $(6.9 \%)$ to chlamydial infections than male $(3.4 \%)$. The Prevalence rate among HIV females was 6 fold greater than in a study carried out among post-partum non-HIV females in rural Nepal. ${ }^{13}$ This chlamydia prevalence among HIV individuals in Nepal is found to be greater than that among female sex worker in Singapore (4.1\%). ${ }^{11}$ These comparisons clearly indicate Nepalese HIV 
females are at greater risk of chlamydial infection. No any such studies were carried out previously among male population. However, the sample size may have been inadequate to give out real picture in this study.

Similar prevalence were reported in Amsterdam $(4.8 \%),{ }^{14}$ England and Wales (5.15 \%). ${ }^{15}$ This prevalence is less than a study conducted in Thailand, where the prevalence rate was 9.7\% among 824 HIV seropositive patients. ${ }^{16}$ The difference can be due to various reasons, as: the specimens used by them were endo-cervical swabs, and the detection method used was gen-probe. In agreement to this, the overall prevalence rate of $C$. trachomatis in cervical scrapes determined by nested PCR was $10 \%$ in 60 Cuban women. ${ }^{17}$ Moreover, in a study conducted in Georgia, the seroprevalence of $C$. trachomatis in 234 HIV patients was $23.94 \%{ }^{18}$ The strongest predicators in these cases were the history of STI and female gender.

The patients participating in this study ranged from 20 years 64 years. The highest numbers of patients $(n=46)$ were from the age group 31-40. Among the five positive cases, three were within age range 2025 year, one was twenty seven and the other was thirty-five years of age. Chlamydia infections mainly affect young people, especially young women. In numerous studies, highest incidence was usually reported in age group below 25 years, accounting for more than sixty percentage of all cases.19,20,21 There are other contradicting studies as well where age group above twenty-five has shown higher prevalence. $22,23,24,25$

Out of total 117 cases, 98 were married and 19 were unmarried. All the positive cases were married. Statistically, no significant association was observed between marital status and occurrence of the disease. Similar insignificant result was observed in a study conducted in Barbados. ${ }^{21}$ In contrast, significant result was observed in another study. ${ }^{26}$ The relation between the knowledge and occurrence of disease was found to be insignificant in our study, which was in harmony with study by Adams et al., 2008. ${ }^{21}$ Of the 117 patients, only $12.8 \%$ knew about the STIs and chlamydia whereas the rest $87.2 \%$ had no idea of the disease. Out of chlamydia positive cases only $40 \%$ knew about STI. This necessitates the increase in effort in disseminating the knowledge of STI to HIV patients as well as to other risk groups.

Asymptomatic cases contributed to $80 \%$ of total positive cases. This nature of the disease leaves patients greatly vulnerable to the devastating effect it brings. Along with it, $96.7 \%$ of symptomatic individuals were negative indicating the difficulty in relying solely on clinical diagnosis of disease. Chlamydia thus possesses high risk to all infected individuals. The lack of resources, as well as, consequences of the disease has made early screening, diagnosis and treatment process very important.

\section{CONCLUSION}

Chlamydia infection is found less common among normal population and most of those cases are asymptomatic therefore go undiagnosed. In contrast, there exists higher prevalence rate among HIV subjects. Asymptomatic nature of chlamydial infection creates difficulty in the timely detection of C. trachomatis as well as its clinical sequel, which might be devastating. Therefore, routine checkup is recommended for all risk groups for timely management of the disease. PCR based diagnostic tests for chlamydia need to be introduced as a part of routine checkup for high risk populations.

CONFLICT OF INTEREST: None to declare.

FINANCIAL INTEREST: None to declare.

\section{REFERENCES}

1. Byrne GI. Chlamydia uncloaked. PNAS 2003;100:8040-8042.

2. Zeidler H, Kuipers J, Kohler L. Chlamydia-induced arthritis. Curr Opin Rheumatol 2004;16:380-392.

3. deGraw M, Shapiro R. Chlamydia trachomatis and sexual abuse: A fact sheet for Non-medical readers. Mayerson Center for safe and healthy children:Cincinnati 2002.

4. Marrazzo JM, Stamm WE. New approaches to the diagnosis, treatment and prevention of Chlamydial infection, In: Current clinical topics in infectious diseases.

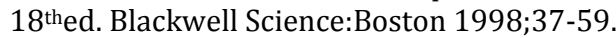

5. Pack RP, Diclemente RJ, Hook EW III, Oh MK. High prevalence of asymptomatic STDS in incarcerated minority male youth: a case for screening. Sex Transm Dis 2000;27:175-177.

6. Boskey E. Chlamydia: an overview. Available from: http://std.about.com/od/bacterialstds/a/chlamydiaover v.htm. Accessed on October 24, 2011.

7. Oh MK, Cloud GA, Fleenor M, Stardevant MS, Nesmith JD, Feinstein RA. Risk for gonococcal and chlamydial cervicitis in adolescent females. J Adolesc Health 1996;8:270-275.

8. Baeten JM, Overbaugh J. Measuring the infectiousness of persons with HIV-1: opportunities for preventing sexual HIV-1 transmission. Current HIV Research 
2003;1:69-86.

9. Joyee AG, Thyagarajan SP, Reddy EV, Venkatesan C, Ganapathy M. Genital Chlamydial infection in STD patients: its relation to HIV infection. Indian J Med Microbiol 2005;23:37-40.

10. Lisby G. Application of nucleic acid amplification in clinical microbiology. Mol Biotechnol 1999;12:75-99.

11. Tan HH, Chan R. Use of polymerase chain reaction on pooled cervical swabs to detect Chlamydia trachomatis infections in female sex works in Singapore. Singapore Med J 2005;46:215-218.

12. Palmer HM, Gilroy CB, Thomas BJ, Hay PE, Gilchrist C, Taylor-Robinson D. Detection of Chlamydia trachomatis by the polymerase chain reaction in swabs and urine from men with non-gonococcal urethritis. J Clin Pathol 1991;44:321-325.

13. Christian P, Khatry SK, LeClerq SC, et al. Prevalence and risk factors of chlamydia and gonorrhea among rural Nepali women. Sex Transm Infect 2005;81:254-258.

14. Van den Hoek JA, Mulder-Folkerts DK, Coutinho RA, Dukers NH, Buimer M, Van Doornum GJ. Opportunistic screening for genital infections with Chlamydia trachomatis among the sexually active population of Amsterdam. Ned Tijdschr Geneeskd 1999;27:668-672.

15. Simms I, Catchpole M, Brugha R, Rogers P, Mallinson $\mathrm{H}$, Nicoll A. Epidemiology of genital Chlamydia trachomatis in England and Wales. Genitourin Med 1997;73:122-126.

16. Srifeungfung S, Roongpisuthipong A, Asavapiriyanont $S$ et al. Prevalence of Chlamydia trachomatis and Neisseria gonorrhoeae in HIV-seropositive patients and gonococcal antimicrobial susceptibility: an update in Thailand . Jpn J Infect Dis 2009;62:467-470.

17. Kouri V, Cartaya J, Rodriguez ME et al. Prevalence of Chlamydia trachomatis in human immunodeficiency virusinfected women in Cuba. Mem Inst Oswaldo Rio de Janeiro 2002;97:1073-1077.

18. Chkhartishvili N, Dvali N, Khechiashvili G, Sharvadze L, Tsertsvadze T. High seroprevalence of Chlamydia trachomatis plasmid DNA by the ligase chain reaction associated with female urines. Clin Microbiol Infect 2010;4:397-404.

19. Cliffe SJ, Tabrizi S, Sullivan EA. Chlamydia in the pacific region, the silent epidemic. Sex Transm Dis 2008;35:801- 806.

20. Malhotra M, Bala M, Muralidhar S, Khunger N, Puri P. Prevalence of Chlamydia trachomatis and its association with other sexually transmitted infections in a tertiary care center in North India. Indian J Sex Transm Dis 2008;29:82-85.

21. Adams OP, Carter AO, Prussia P, McIntyre G, Branch SL. Risk behavior, healthcare access and prevalence of infection with Chlamydia trachomatis and Neisseria gonorrhoeae in a population-based sample of adults in Barbados. Sex Transm Infect 2008;84:192-194.

22. Vetter KM, Barnes RC, Oberle MW, et al. Seroepidemiology of Chlamydia in Costa Rica. Genitourin Med 1990;66:182-188.

23. Haley N, Roy E, Leclerc P, et al. Risk behaviors and prevalence of Chlamydia trachomatis and Neisseria gonorrhoeae genital infections among Montreal street youth. International Journal of STDs and AIDS
2002;13:238-245.

24. Tabora N, Zelaya A, Bakkers J. Chlamydia trachomatis and genital human papillomavirus infections in female university students in Honduras. Am J Trop Med Hyg 2005;73:50-53.

25. Leung PH, Boost MV, Lau JT, et al. Prevalence and risk factors for Chlamydia trachomatis among cross-border truck drivers in Hong Kong. Sex Transm Infect 2009;85:27-29.

26. Hillard SW, Gail AB, Robert K, Carlos B, Arthur B, Geraldine 0. Chlamydia trachomatis infection in women: a need for universal screening management in high prevalence populations? Am J Epidemiol1992;354:17761781.

\section{Citing this article}

Shrestha A, Adhikari N, Shah Y, Poudel P, Acharya B, Pandey BD. Chlamydia trachomatis detection in HIV infected patients using PCR technique. Int J Infect Microbial 2013;2(1);12-16. 